\title{
Irrigation Pivot-Center Connected At Low Cost For The Reduction Of Crop Water Requirements
}

\author{
Olivier Debauche \\ Computer Science Unit \\ Faculty of engineering - UMons \\ Mons, Belgium \\ olivier.debauche@umons.ac.be \\ Pierre Manneback \\ Computer Science Unit \\ Faculty of engineering - UMons \\ Mons, Belgium \\ pierre.manneback@umons.ac.be
}

\author{
Meryem El Moulat \\ Remote Sensing \& GIS Unit \\ Faculty of Sciences - UMV \\ Rabat, Morocco. \\ m.elmoulat@gmail.com \\ Frédéric Lebeau \\ BioDynE Axis \\ GxABT - ULiège \\ Liège, Belgium \\ f.lebeau@uliege.be
}

\author{
Saïd Mahmoudi \\ Computer Science Unit \\ Faculty of engineering - UMons \\ Mons, Belgium \\ said.mahmoudi@umons.ac.be
}

\begin{abstract}
Irrigation, particularly pivot-center, is widely used around the world to fill the need of crop watering. This method of irrigation has a low efficiency compared to other methods of irrigation such as drip systems and generally they use water without consider the real need of plants. In this paper we propose an automation system based on the Internet of Things (IoT), Geographic Information System (GIS) and quasi real-time in the cloud of water requirements to improve the efficiency of water use. Indeed, each segment of the pivot-center moves at a different speed compared to others; thus, must be individually controlled to optimize the yield of irrigation. Moreover, it necessary to integrate factors such as stage of crops' development, heterogeneity of soil, runoff, drainage, soil components, nutrients and moisture content. In this paper we develop a complete system integrating sensors, GIS, Internet of Things and cloud computing. This approach allows to automate fine-grained the consumption of water without decreasing the yield. In addition to that, the collect of data and the soil moisture measurement will allow to adapt coefficient of evapotranspiration to local weather without having to resort to lysimetric measures. The proposed architecture allows to store and treat real-time, time series data and low-priority data such as 3D images used in digital phenotyping field which are treated with batch processing.
\end{abstract}

Keywords—smart farming, smart environment, precision agriculture, connected irrigation, water requirements

\section{INTRODUCTION}

The demand of food production and fiber increase with de world population. The irrigation management is important particularly in context where the fresh water resources are limited. The aim of the irrigation is to give to plants the adequate amount of water to ensure their water requirements. The use of Water Production Function (WPF) allows to estimate the production in terms of dry matter or marketable yield, evapotranspiration or the amount of applied water during irrigation (IW). According to the different production functions of IW may also include different components in addition to Crop Water Requirement (CWR), such as pre-planting irrigation to prepare the seeding, leaching requirement to decrease the salinity, rise of water table by capillarity and rainfall.

The estimation of water requirement is a stone corner which you can calculate the correct irrigation doses. Indeed, the water available for the crop is an indicator of the texture of soil, precipitations, previous irrigations, state of development of crop and the amount of water already present in the soil. Center-Pivot of irrigation are usually reserved to irrigate large areas from 3.5 to 65 ha because of the costs; but, the nutrients, fertilizer, herbicide, insecticide and pesticide can be directly applied on the canopy of crop [1].Center-Pivot irrigation systems require up to $40 \%$ less water application than traditional and conventional gravity (furrow) or surface irrigation methods, where a part of water is lost by percolation or runoff. But Center-pivot irrigation stays less effective than the drip systems that are the most economical in term of water. The main challenge is related to the exact estimation of both the evapotranspiration of the crop and how to bring the water (frequency and quantity). Traditional hand-feel soil measurement methods do not provide quantitative soil water and real-time data. The use of sensors in precision agriculture is becoming widespread, especially in irrigation and open the field of irrigation management in order to establish an optimal timing and amount of irrigation water for greatest effectiveness. Indeed, an optimal irrigation management avoid water deficiency and use too much water that reduces the potential for profitability of the crop. The supply of an optimal amount of water allows also to maximize the yield response to other management practices, optimize yield per unit of water applied, reduce the potential runoff, reduce soil erosion and pesticide movement into the surface and ground water [1].

To optimize the yield and soil water in the crop, plants should not pass the wilting point. This means the minimum 
soil moisture required by a plant not to wilt. At this point, any decrease in soil moisture will result in wilting. When a plant wilts, its leaves dry out, droop, and wither. The coupling of the irrigation system with a soil moisture monitoring and an accurate evapotranspiration calculation has a significant advantage in term of water consumption. Precision agriculture (PA) uses the Internet of Things and allows real-time control measure and automation of pivot-center irrigation systems. Furthermore, Wireless Sensors Network (WSN) is affordable and the wide availability of Low Power Wide Area (LPWA) protocol such as LoRa, SigFox and Ingenu coupling with cloud IoT platforms pave the way of high precision and realtime irrigation management systems.

In this paper, we combine agronomic and computer science expertise to propose a cloud IoT architecture and a network of sensors using LPWA to control, monitor and optimize the crop production at quasi real-time. The low-cost sensor network measure on one hand the weather data required to calculate potential evapotranspiration of the crop, and on other hand the soil moisture at different depths. The proposed architecture calculates water requirements of plants and actuate solenoids to open and close water individually each sprinkler.

\section{LITERATURE REVIEW}

The main challenges in the elaboration of an automated irrigation system for irrigation pivot-center are vital; on one hand to choose an adapted evaluation method of water requirements, and on other hand to identify a correct cloud IoT platform essential for data storage and treatment. The following paragraph focuses on these aspects and on reviewing existing works.

\section{A. Related works}

Classical Water Production Functions (WPF) are useful tools for irrigation management and economic analysis of yield reduction due to deficit irrigation which is usually based on linear regression and don't give a representation of nonlinear behaviors of complex ecological systems. To fix this issue recent research are investigated. We list the use of more robust and nonlinear techniques such as machine learning, Artificial Neural Network (ANN) and data-mining tools (e.g. Fortin et al in 2010 [2], Dai et al. in 2011 [3], Haghverdi et al. in 2014 [4] and Elnesr et al., in 2016 [5]). In this study we follow two different controls. The first model consists to control the speed of travelling of the central-pivot for a constant flow rate. The second uses an electronic control to adapt flow rate in the nozzles. The speed of travelling of the central-pivot is maintained constant. The variable rate irrigation (VRI) allows to save 9-19\% of irrigation water and to address field-level spatio-temporal heterogeneity in terms of soil water holding capacity and depth of soil [6]. According to Pan et al in 2013 [7] VRI allows also to enhance water-use efficiency, improve productivity, reduce fuel consummation and reduce nutrient leaching. The choice of sprinkler package, the pressure of working, meteorological conditions and tower dynamics affect the irrigation water distribution pattern [8]. Moreover, variations in micrometeorological and technical conditions can modify the water application depth and irrigation uniformity at different lateral positions with flow control nozzles or pressure regulators at each head [8]. Wind speed and direction don't significantly modify the uniformity of water application but impact the absolute application depth of zones under VRI management [9]. To adapt flow of irrigation soils moisture measure must be done. Traditional soil moisture sensors need to be installed early in the growing season and must be removed before the harvesting. Dong et al in 2013 [1] has proposed a cyberphysical system based on underground sensors to monitor soil moisture but this approach do not monitor soil on only one depth [1].

The interest of the coupling of Geographic Information System (GIS) and Remote Sensing (RS) with Internet of Things (IoT) has been demonstrated by different authors such as Li et al. in 2012 [10] Ye et al. in 2013 [11] Wang et al., 2013 [12].

\section{B. Estimations of water requirements}

The estimation of water requirements of a crop (ETc) can be estimated from a simple soil water balance (SSWB) model. A general form of the soil water balance is done by the following equation:

$$
\mathrm{ETc}=\mathrm{I}+\mathrm{P}+\mathrm{F}+\mathrm{R}+\Delta \mathrm{S}
$$

Where $I$ is the irrigation dose [mm], $P$ is the precipitation [mm], $F$ is the net subsurface flow into the control volume [mm], $R$ is net runoff or runon to the control volume surface $[\mathrm{mm}]$ and $\Delta S$ is the net change in soil water stored in the control volume [mm].

The potential evapotranspiration (PET) can be calculated by using different methods. A common one requires several weather data that are not all the time available. Among these methods, we mention Penman-Monteith [13] FAO56 PM) which ranked as the best method for estimating daily and monthly ET for all climates. Penman [14] (FAO24), Penman [15] (FAO-ppp-17), Kimberly-Penman [16], Hamon [17], Hargreaves [18], Haude [19], Penman [20], PenmanMonteith [21], Priestley-Taylor [22], Makkink [23], $\mathrm{McCl}$ [24], De Bruin-Keijman [25] (DK), Jensen-Haise [16], Blaney-Criddle [26] (BC), Blaney-Criddle [14] (FAO 24 BC), FAO 24 Radiation [14], Turc [27], Wendling [28], Valiantzas [29]. Nevertheless, modern technologies such as the use of Wireless Infrared Thermometers (IRT) appear to measure surface temperature and determine the ETc [30]. A comparison of 16 among the models mentioned above has been carried out by Liu et al. in 2017 [31] and have shown that FAO-ppp-17, Pen-63 and FAO-24 BC are the better results in semi-arid climate. Therefore, we notice that a poor calibration between all the aforementioned researchers lead to inconsistent results of existing studies on weighting lysimeter. Indeed, Jensen et al. report that FAO24BC is better [32]. While Yoder et al. in 2005 [33] and López-Urrea et al. in 2006 [34] find that FAO56 PM is the better formula. Otherwise some authors such as Berengena et al. in 2005 [35], Howell et al. in 1998 [36] have proven that the adjustment of the Penman formula coefficients at local scale shows significantly performing results. To conclude, we assume that FAO56 PM or FAO24 BC can be tested as a first 
approach in the evaluation of the evapotranspiration and a precise evaluation can be obtained locally by adjusting the parameters of the original Penman equation. The local adjustment of coefficient of the Penman formula need the use of lysimeters and a long experimentation which is not always achievable out of research centres.

The Maximal Evapotranspiration (MET) of a crop can be calculated at different vegetative stage when amount of water is sufficiently available and agronomic condition are optimal. The MET can be calculated by model but in real conditions, and the Real Evapotranspiration (RE) is inferior in amount calculated by model. By consequence, it's important to measure accurately real evapotranspiration by mean of sensors to provide the necessary quantities of water and to avoid percolation losses related to excessive intake linked in particular to an overestimation of the actual evapotranspiration.

\section{Choice of sensors}

Both approaches can be followed. The first one uses commercial sensing solutions which natively provide a wide range of features directly and allows researchers to focus on the developments of algorithms and meta-processing, etc. The second one uses open hardware solutions which are programmable and flexible allowing to developers to have the full control of the behaviors of the nodes [37] The first approach is particularly interesting to develop proof of concept but makes researchers dependent of one provider and the availability of sensors used for development. Moreover, the rapid turnover of product of high technology renders this science stream especially risked for long term developments. The second way although requiring further development is more sustainable and is generally supported by a large community of developers.

The choice of sensors is crucial because nodes can move over time that causes considerable interferences in the communication between nodes. Moreover, the influence of temperature, humidity, rainfall, sandstorm and high solar radiation greatly affect the links and communication quality among the nodes, particularly in harsh environmental conditions. The high temperature encountered in semiarid environments affects significantly the received signal strength (RSS). The humidity linked to the irrigation system and the heavy rainfall intensely affects the propagation of radio waves. The choice of the wireless transceiver and the transmission protocol must take into account the number of nodes, the distances between them, the height of antenna and the operating frequency based on the desired size of payload [37].

\section{Cloud IoT platform}

The correct choice of the IoT Platform to build a solution can affect the overall success of the project [37]. Both explorable approaches acquire and manage the underlying hardware and software layers or use a commercial offering which provides all needed services to propose an integrative solution. A review proposed by Ray PP in 2016 compare the 26 most popular IoT cloud platforms based on the following parameters: deployment service, device management, system management, heterogeneity management, data management, tools for analysis, deployment, monitoring, visualization and research. According to Ray in 2016 [38], they should have at least 49 IoT cloud platforms present in the actual global market. Nowadays, any commercial or open source cloud platform allows to deploy, and hosts applications or models elaborated on different framework on the same cloud architecture.

\section{Calculation of Water Requirements}

The soil characterization has been achieved on basis of samples taken in situ by BNEDER (National Technical Studies Office for Rural Development) located at Alger (Algeria). 96 samples were taken following a systematic grid of $30 \times 30 \mathrm{~m}$ over the area covered by the pivot (one by layer of soil). The parameters evaluated were bulk density, texture and the soil water holding capacity. Then, parameters measured on each of the 32 sampling points for three layers of soil has been interpolated to obtain a high-resolution map. The software ArcMap 10.5.1 was used to interpolate data measured in order to generate a grid by layer of $5 \mathrm{~m} \times 5 \mathrm{~m}$ $\left(25 \mathrm{~m}^{2}\right.$ area per cell) for each kind of measure. Moreover, each layer of soil has also been interpolate using 3D spline method to obtain a 3D model of soil layer. This 3D model and the spatial interpolation of soil water holding capacity allows to calculate the plant available in function of the depth of rooting. As shown on Fig. 1.

The first layer is a mix of one or more existing layers which have been homogenized from a textural point of view and the salt content by successive plowing on a height of 25 to $30 \mathrm{~cm}$. The water available for plant is also function of roots development which offers the possibility to explore a more and more large part of soil. The available water is obtained by a weighted mean of the depth of all layers explored by the root system at each stage of development. A day by day amount of water irrigation can be calculated from (1). 


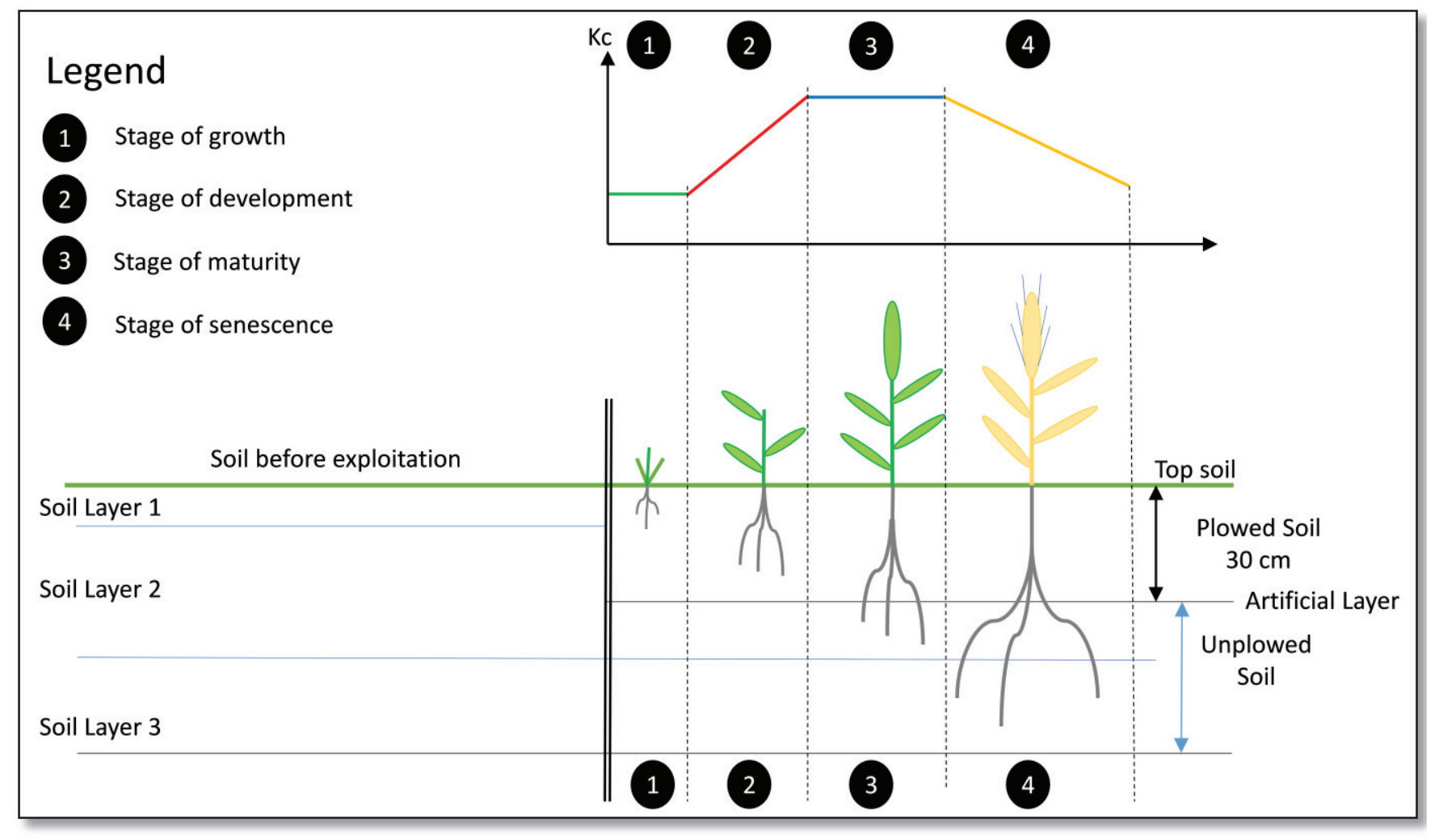

Fig. 1 Different stages of crop development

The FAO Penman-Monteith method (2) is used to estimate the potential evapotranspiration (PET) and the evapo-transpiration of the crop $(E T c)$, also named MET which takes into account the stage of vegetative growth of the crop by weighting the potential evapotranspiration by the coefficient $K c$ [13]. The $K c$ coefficient allows to modulate the $P E T$ in function of the crop envisaged and the stage of its stage of development.

$$
E T P=\frac{0.408 \Delta\left(R_{n}-G\right)+\gamma(900 / T+273) U_{2}\left(e_{s}-e_{a}\right)}{\Delta+\gamma\left(1+0.34 U_{2}\right)}
$$

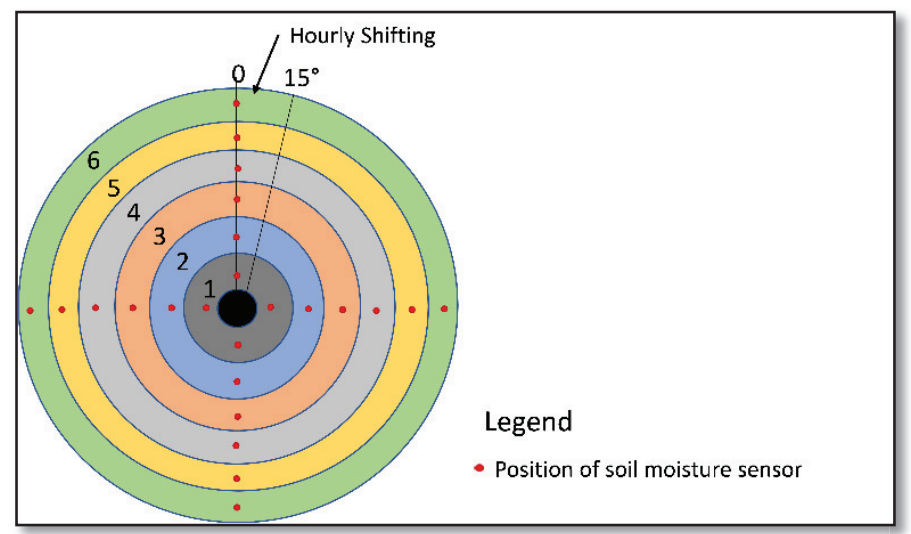

Fig. 2 Cutting of irrigated perimeters in 6 zones and positioning of the soil moisture sensors
Where PET is the reference evapotranspiration [mm.day $\left.{ }^{1}\right], R n$ is the net radiation at the crop surface $\left[\mathrm{MJ}^{2} \mathrm{~m}^{2}\right.$. day $\left.{ }^{-1}\right], G$ is the soil heat flux density [MJ.m ${ }^{-2}$.day $\left.{ }^{-1}\right], T$ is the mean daily air temperature at $2 \mathrm{~m}$ height of soil $\left[{ }^{\circ} \mathrm{C}\right], U_{2}$ is the wind speed at $2 \mathrm{~m}$ height of soil $\left[\mathrm{m} \cdot \mathrm{s}^{-1}\right], e_{s}-e_{a}$ is the saturation vapor pressure $[\mathrm{kPa}], \Delta$ is the slope of the vapor pressure curve $\left[\mathrm{kPa} .{ }^{\circ} \mathrm{C}^{-1}\right], \gamma$ is the psychrometric constant $\left[\mathrm{kPa} .{ }^{\circ} \mathrm{C}^{-1}\right]$. The evapotranspiration of the crop is calculated with (3).

$$
\mathrm{ETc}=\mathrm{PET} * \mathrm{Kc}
$$

Where ETc is the crop evapotranspiration [mm.day ${ }^{-1}$, PET is the reference evapotranspiration $\left[\mathrm{mm} . \mathrm{day}^{-1}\right]$ and $\mathrm{Kc}$ is a ponderation coefficient variating between 0.3 to 1.2 depending of the crop stage of development [8], see Fig 1.

\section{MATERIAL}

The application is tested on a pivot-center irrigation and a crop of soft wheat implanted in Ain Salah located in the heart of the Sahara Desert region in the center of Algeria. This region is characterized by a hot desert climate where the temperature in the summer reach 47 to $50^{\circ} \mathrm{C}$. The irrigation pivot-center is composed of 6 spans with a total length of $308 \mathrm{~m}$. The revolution time of the pivot is $24 \mathrm{~h}$, it means that every hour an angle of $15^{\circ}$ is traveled. As shown in the Fig. 2 , the cover area is increasing from the center to the outside. The sensors must stay functional with important temperature variation from 20 to 65 degrees and remained functional also in presence of rate of humidity close to $80 \%$. 


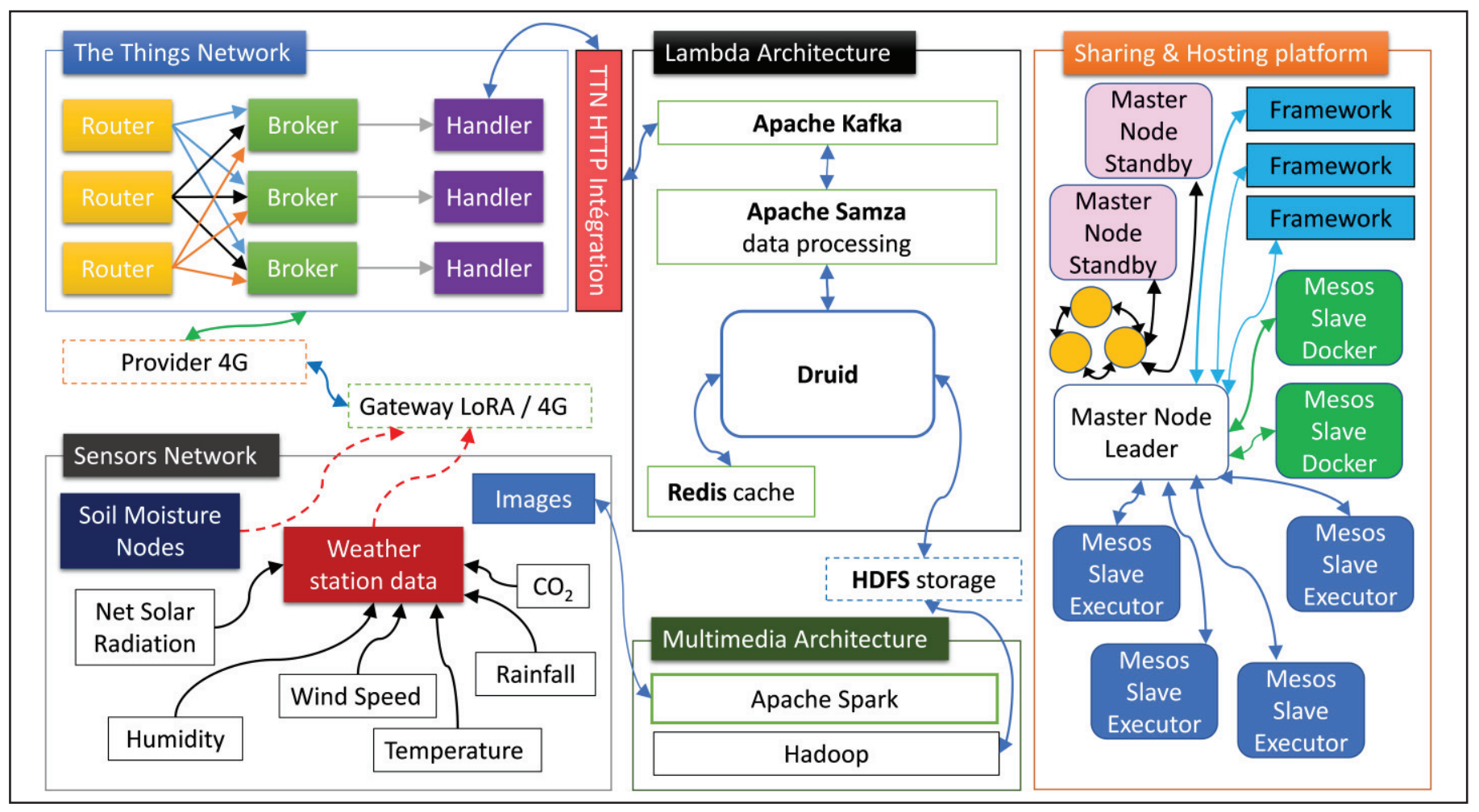

Fig. 3 The Proposed System and Architecture

\section{Proposed System And ARChitecture}

We have chosen to follow the open hardware way as part of our developments. The proposed system is composed locally of a weather station. Several multi-depth moisture sensors distributed on the irrigate area at the middle on each span measure the amount of water at different depths and solenoid placed on sprinkler. Data are transmitted by LoRa modulation to a gateway which relay data to The Things Network using a 4G connection. A cloud architecture collects, treats and stores data received from the weather station and soil moisture sensor, and calculates in real-time needs in irrigation water.

\section{A. Weather Station}

The weather data are acquired by a micro weather station which uses a LoRa transmission system. This low-cost protocol has been chosen for its easiness of deployment, its ability to resist interference with the spread spectrum technology and the area that can be covered by a single gateway. The micro weather station is based on a Weather Sensor (Argent Data Systems) which contains an anemometer, a vane direction and a pluviometer. The weather station contains a temperature / humidity sensor AM2315 (Aosong) with an error of $0.1^{\circ} \mathrm{C}$ for the temperature and $2 \%$ for the relative humidity. The net solar radiation is measured by a digital net radiometer SN-500, Apogee Instruments. All sensors are connected on a LoPy which collect data and send them on LoRa / 4G gateway (see Fig. 3).

\section{B. Sensors and actuators}

Soil moisture nodes based on LoPy using soil moisture underground sensors measure the rate of humidity at different soil depths. The humidity is measured at different depth (20, 30 and $50 \mathrm{~cm}$ ) with Watermark Soil Moisture Irrometer sensor model 200SS. The measure of humidity at different depth allow to control if amount of water calculate are correct or if they must be adjusted. As show on Fig. 2, the 24 sensors are implanted in the middle of each ring, the water requirements are controlled 8 times per day (one just before the irrigation and one hour just after the irrigation) on each of the four control lines of sensors.

Solenoid valves are implanted on the sprinkler feed pipes and allows them to be operated individually and thus finely control the water supply. The fine control of the sprinklers allows to have a same amount of water per unit area at each of the 6 zones traveled at the level of each of the different segments each hour.

\section{Cloud Architecture}

We use our own architecture based on a Cloud IoT platform and a share/hosting application platform. This architecture has already been tested with cattle behavior [39], digital phenotyping [40] and monitoring of bee health [41]. Time-related Data are transmitted to the Cloud IoT platform by LPWA network while images, videos and sound are transmitted by Wi-Fi network, see Fig. 3. 


\section{1) The cloud IoT platform}

The platform is composed of two parts. The first one is based on one hand on Apache Kafka, Apache Samza, Druid, to treat stream and time-related data. The second one uses an Apache Hadoop, Apache Spark are associate to store and treat images, sound and video.

\section{a) Time related-data}

Data are received by Apache Kafka which transfer them to Apache Samza to be processed before the ingesting by Druid. Druid is a distributed column-oriented fault-tolerant data store presenting real-time analytical capabilities. The data processing allows to increase the speed of ingestion 10 times by elimination of bad formed package, inconsistent and incomplete data. Redis Caching accelerate the speed of recurrent queries. The data are stored in units of few millions of lines named 'segments' composed of 5 to 10 million of times-stamped events compressed by LZ4. Old segments are locally stored on HDFS. Both external dependencies are used: PostgreSQL and ZooKeeper to respectively store meta data and monitor the four kinds of nodes present in the cluster. These four types of nodes coordinate, broke, store in real-time or archive data in the distributed data store.

\section{b) Sound, Images and Video}

These kinds of data are independently treated and stored by a second structure based on Hadoop and Apache Spark. These kinds of data are also locally stored on HDFS. This structure offers better performance than an Hadoop, MapReduce, HiPi. Camera placed on the pivot center can make 3D-pictures of same plant every day in order to model their development and compare the impact of agricultural practices and weather conditions on the growth of the crop. The analysis of sound allows to detect any dysfunction may occur of critical parts of pivot-center and program a preventive maintenance (PM) to avoid the immobilization of the pivot over a long period. But both features are not yet implemented.

\section{2) The application sharing and hosting platform}

Druid powers high performances application with low query latencies. To better exploit this performance and don't be dependent of one SDK, we propose a cloud architecture able to host application developed on principal framework. This cloud platform authorizes elaboration of the model by researchers and also host endpoint applications of third party adapted to different kinds of material allowing to monitor and automate the pivot-center irrigation while optimizing crop yields.

\section{RESULTS}

We compare water requirements calculated by the cloud architecture with the one calculated by CropWat [42] decision support tool. This tool is developed by the Land and Water Development Division for the calculation of crop water requirements and irrigation requirements based on soil, climate and crop data. The calculation procedure is described in [8], the response of different yield is explained in [43] and the coupling between CropWat and climatic data of ClimWat is explicated step by step in [44]. Remarkably values calculated by CropWat assume that only water can change and other factors such as agricultural practices, fertilization, etc. are at optimal level. Table 1 gives results obtained with CropWat 8.0 for a wheat with a planting date of 25 November at In Salah, Algeria and total development in 180 days. Water requirements are calculated on basis of real daily weather data.

TABLE I. WATER REQUIREMENTS CALCULATED WITH CROPWAT

\begin{tabular}{|c|c|c|c|c|}
\hline \multirow{2}{*}{ Month } & \multirow{2}{*}{ Decade } & \multirow{2}{*}{ Stage } & $\mathrm{Kc}$ & \multirow{2}{*}{$\begin{array}{c}\text { ETc } \\
m / d a y\end{array}$} \\
\hline & & & Coeff & \\
\hline November & 3 & Initial & 0.30 & 1.04 \\
\hline December & 1 & Initial & 0.30 & 0.90 \\
\hline December & 2 & Initial & 0.30 & 0.77 \\
\hline December & 3 & Initial & 0.30 & 0.78 \\
\hline January & 1 & Development & 0.35 & 0.95 \\
\hline January & 2 & Development & 0.54 & 1.46 \\
\hline January & 3 & Development & 0.74 & 2.19 \\
\hline February & 1 & Mid-season & 0.94 & 3.01 \\
\hline February & 2 & Mid-season & 1.12 & 3.86 \\
\hline February & 3 & Mid-season & 1.16 & 4.42 \\
\hline March & 1 & Mid-season & 1.16 & 4.85 \\
\hline March & 2 & Mid-season & 1.16 & 5.28 \\
\hline March & 3 & Mid-season & 1.16 & 5.89 \\
\hline April & 1 & Mid-season & 1.16 & 6.51 \\
\hline April & 2 & Late season & 1.10 & 6.76 \\
\hline April & 3 & Late season & 0.89 & 5.71 \\
\hline May & 1 & Late season & 0.68 & 4.52 \\
\hline May & 2 & Late season & 0.46 & 3.20 \\
\hline May & 3 & Late season & 0.32 & 2.26 \\
\hline & & & Total & 623.8 \\
\hline
\end{tabular}

The Fig. 4 shows the comparison between measured and calculated with CropWat Potential Evapotranspiration (ETP). Both approach gives similar results.

\section{CONCLUSION AND FUTURE WORKS}

We have outlined an architecture based on soil characteristics interpolate by mean of GIS, soil moisture measured, and weather data transmitted by LoRaWan to calculate in quasi real-time the water requirements of the crop. The LoRaWan is particularly adapted to transmit data in harsh conditions. In the end, the comparison of first approach performed with CropWat has allowed to calculate maximal evapotranspiration and verify that these are never exceeded. 


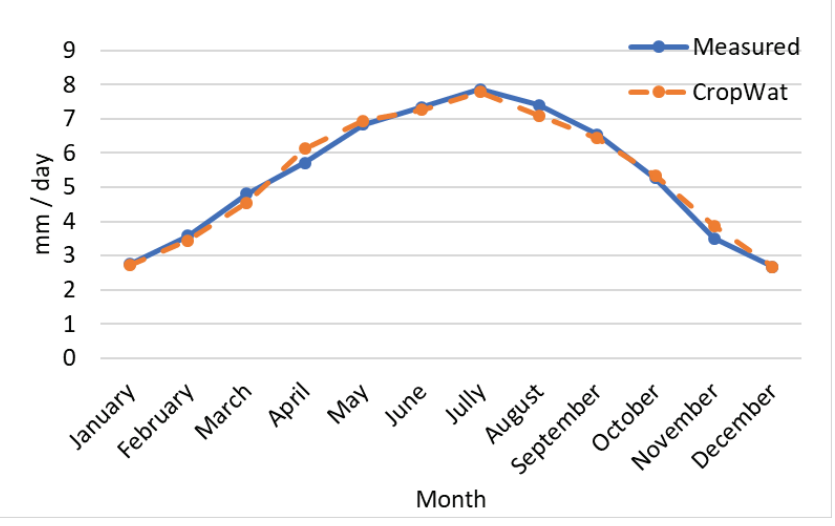

Fig. 4 Comparison between CropWat and Measured average daily ETP

In order to validate the water requirements calculated using the CropWat model, we compared them with a precise model called AquaCrop [45]. This model considers more parameters affecting the vegetative and reproductive growth of crop.

The implementation of 3D Camera in specific areas places on the pivot, will open a new research path in the field of digital phenotyping. In addition to this, the continuous analysis of sound from microphones implemented in chosen places will quickly detect signs of failure and prevent downtime that can be expensive in term of crop profitability. As future work, we plan to exploit GPU Tegra Mobile Processors ${ }^{1}$ that offers high computation power thanks to the exploitation of GPU processors in parallel [46] [47]. In addition to the high performance, these cards provide the possibility to exploit artificial intelligence algorithms for a better training and prediction of collected data.

\section{ACKNOWLEDGMENT}

We would like to thank our colleagues from Biosystems Dynamics and Exchanges Axis, Biosystem Engineering Department, Gembloux Agro-Bio Tech (ULiège) without whom this work would not have been possible. We would especially like to thank Mr Rudy Schartz and Mr Adriano Guttadauria for their technical support and for setting up all the electronic systems and computing systems necessary for carrying out this research.

\section{REFERENCES}

[1] X. Dong, M. Vuran and S. Irmak, "Autonomous precision agriculture through integration of wireless underground sensor networks with center pivot irrigation systems," Ad Hoc Network, vol. 11(7), pp. 1975-1987, 2013.

[2] J. Fortin , F. Anctil, L. Parent and M. Bolinder, "A neural network experiment of the site-specific simulation of potato tuber growth in Easter Canada," Computers and Electronics in Agriculture, Vols. 126132, p. 73(2), 2010.

[3] X. Dai, Z. Huo and H. Wang, "Simulation for response of crop yield to soil moisture and salinity with artificial neural networks.," Field Crops Res, vol. 121(3), pp. 441-449, 2011.

[4] A. Haghverdi, B. Ghahraman , B. Leib , I. PulidoCalvo, M. Kafi , K. Davary and B. Ashorum, "Deriving data mining and regression based watersalinity production functions for spring wheat (Triticum aestivum)," Computers and Electronics in Agriculture, vol. 101, pp. 68-75, 2014.

[5] M. N. Elnesr and A. A. Alazba, "Simulation of water distribution under surface dripper using artificial neural networks," Computers and Electronics in Agriculture, vol. 143, pp. 90-99, 2017.

[6] A. Haghverdi, B. Leib , R. Washington-Allen and M. Buschermohle, "Studying uniform and variable rate center pivot irrigation strategies with the aid of sitespecific water production functions," Computers and Electronics in Agriculture, vol. 123, pp. 327-340, 2016.

[7] L. Pan , V. Adamchuk, D. Martin , M. Schroeder and R. Ferguson, "Analysis of soil water availability by integrating spatial and temporal sensor-based data," Precision Agriculture, vol. 14(4), pp. 414-433, 2013.

[8] S. Ouazaa, B. Latorre, J. Burguete, A. Serreta, Playán E and R. Salvador, "Effect of the start-stop cycle of center-pivot towers on irrigation performance:

Experiments and simulations," Agricultural Water Management, vol. 147, pp. 163-174, 2015.

[9] S. O'shaughnessy, Y. Urrego, S. Evett, P. Colaizzi and T. Howell, "Assessing application uniformity of a variable rate irrigation system in a windy location," Applied Engineering in Agriculture, vol. 29(4), pp. 497-510, 2013.

[10] X. Li, L. Peng and C. Sun, "The Application and Forecast of Geospatial Information Technology in Agriculture Internet of Things," in 2nd international conference on remote sensing, environment and transportation engineering, Sète, 2012.

[11] J. Ye, B. Chen, Q. Liu and Y. Fang, "Precision Agriculture Management System Based on Internet of Things and WebGIS," in 21st international conference on geoinformatics, Kaifeng, China, 2013.

[12] L. Wang, J. Xiong and Y. Du, "Study on the detection and warning system of rice disease based on the GIS and IOT in Jilin Province," IFIP Advances in Information and Communication Technology, vol. 393(Part 2), pp. 168-176, 2013.

\footnotetext{
${ }^{1}$ Tegra Mobile Processors :http://www.nvidia.com/object/tegra.html
} 
[13] R. G. Allen, L. S. Pereira, D. Raes and M. Smith, Crop Evapotranspiration: Guidelines for Computing Water Requirements., Rome: FAO, 1998.

[14] J. Doorenbos and W. Pruitt, Crop water requirements, Rome: FAO, 1977.

[15] M. Frére and G. Popov, Agrometeorological Crop Monitoring and Forecasting Plant Production and Protection, Rome: FAO, 1979.

[16] M. Jensen and H. Haise, "Estimating evapotranspiration from solar radiation," Journal of the Irrigation and Drainage Division. American Society of Civil Engineers, 1963.

[17] W. R. Hamon, "Estimation potential evapotranspiration," J. Hydraul. Div. Proc. Am. Soc. Civ. Eng., no. 87, pp. 107-120, 1961.

[18] G. H. Hargreaves and Z. A. Samani, "Reference crop evapotranspiration from temperature.," Applied Engineering in Agriculture, vol. 1, no. 2, pp. 96-99, 1985.

[19] W. Haude, "Zur bestimmung der verdunstung auf möglichst einfache weise.," Mitt. Dtsch.

Wetterdiesnstes, vol. 2, no. 11, pp. 1-24, 1985.

[20] H. L. Penman, Vegetation and Hydrology, Tech. Comm n53 ed., C. B. o. soils, Ed., Harpenden, 1963.

[21] J. L. Monteith, Evapotranspiration and the environment.

[22] C. H. B. Priestley and R. J. Taylor, "On the assessment of surface heat flux and evapotranspiration using large scale parameters," Mon. Weather Rev., vol. 100, no. 2, pp. 81-92, 1972.

[23] G. Makkink, "Testing the Penman formula by means of lysimeters," J. Inst. Water Eng, vol. 11(3), pp. 277278, 1957.

[24] D. McCloud, "Water requirements of fields crops in Florida as influenced by climate," Proc. Soil. Sci. Soc. Fla, vol. 15, pp. 165-172, 1955.

[25] H. De Bruin and J. Keijman, "The Prietsley-Taylor evapotranspiration model applied to a large shallow

lake in the Netherlands," Journal of Applied Meteorology, vol. 18, pp. 898-903, 1979.

[26] H. Blaney and W. Criddle, "Determining Water Requirements in Irrigated Ares from Climatological and Irrigation Data," Utah, USDA, 1, p. 50.

[27] L. Turc, "Evaluation des besoins en eau d'irrigation, évapotranspiration potentielle, formule climatique simplifiée et mise à jour," Ann. Agron, vol. 12(1), pp. 13-49, 1961.

[28] U. Wendling, "Zur messung und schätzung der potentielle verdunstung," Ztg. Meteorol, vol. 25(2), pp. 103-111, 1975.

[29] K. Djaman, K. Koudahe, S. Allen, M. O'Neill and S. Irmak, "Validation of Valiantza's Reference Evapotranspiration Equation under Diffrent Climatic
Conditions," Irrigation \& Drainage Systems Engineering, vol. 6, no. 3, p. 196, 2017.

[30] P. Colaizzi, S. O’Schaughnessy, S. Evett and R. Mounce, "Crop evapotranspiration calculation using infrared thermometers aboard center pivots," Agricultural Water Management, vol. 187, pp. 173189, 2017.

[31] X. Liu , C. Xu, X. Zhong, Y. Li and X. Yuan, "Comparison of 16 models for reference crop evapotranspiration against weighting lysimeter measurement," Agricultural Water Management, vol. 184, pp. 145-155, 2017.

M. Jensen, R. Burnman and R. Allen,

"Evapotranspiration and irrigation water requirements," ASCE Manuals and Reports on Engineering Practices, New York, 1990.

[33] R. Yoder, L. Odhiambo and W. Wright, "Evaluation of methods for estimating daily reference crop evapotranspiration at a site in the humid southeast United States," Applied Engineering in Agriculture, vol. 21(2), pp. 197-202, 2005.

[34] R. López-Urrea , O. Martin de Santa , C. Fabeiro and A. Moratalla, "Testing evapotranspiration equations using lysimeter observations in semiarid climate," Agricultural Water Management, vol. 85, pp. 15-26, 2006.

[35] J. Berengena and P. Gavilán, "Reference evapotranspiration estimation in a highly advective semiarid environment," Journal of Irrigation and Drainage Engineering, vol. 131(2), pp. 147-163, 2005.

[36] T. Howell, S. Everett, A. Schneider, R. Todd RW and J. Tolk, "Evapotranspiration of irrigated fescue grass in a semi-arid environment," in ASAE Annual

International Meeting, Joseph (MI), 1998.

[37] A. Tzonis, N. Katsoulas and T. Bartzanas, "Internet of Things in agriculture, recent advances and future challenges," Biosystems Engineering, vol. 164, pp. 3148, 2017.

[38] P. Ray, "A survey of IoT cloud platforms," Future Computing and Informatics Journal, Vols. 35-46, p. 1, 2016.

[39] O. Debauche, S. Mahmoudi, A. L. H. Andriamandroso, P. Manneback, J. Bindelle and F. Lebeau, "Web-based cattle behavior service for researchers based on the smartphone inertial central," Procedia Computer Science, no. 110, pp. 110-116, 2017.

[40] O. Debauche, S. Mahmoudi, P. Manneback, M. Massinon, N. Tadrist, F. Lebeau and S. A. Mahmoudi, "Cloud architecture for digital phenotyping and automation," in 3rd International Conference of Cloud Computing Technologies and Applications (CloudTech), Rabat, 2017. 
[41] O. Debauche, M. Elmoulat, S. Mahmoudi, S. Boukraa, P. Manneback and F. Lebeau, "Web Monitoring of Bee Health for Researchers and Beekeepers Based on the Internet of Things," in The 8th International Symposium on Frontiers in Ambient and Mobile Systems (FAMS 2018), Porto, 2018.

[42] M. Smith, "CROPWAT: A computer program for irrigation planning and management," in Food \& Agriculture Org, Rome, 1992.

[43] P. Steduto, T. C. Hsiao, E. Fereres and D. Raes, Crop yield response to water, Rome: FAO, 2012.

[44] O. Debauche and N. Tadrist, "Climat 2.0 \& Cropwat 8.0," 2012.

[45] P. Steduto, T. C. Hsiao, D. Raes and E. Fereres, "AquaCrop - The FAO crop model to simulate yield response to water: I. Concepts and underlying principles.," Agronomy Journal, vol. 101, no. 3, pp. 426-437, 2009.

[46] S. A. Mahmoudi and P. Manneback, "Multi-GPU based Event Detction and Localization using High Definition Videos," in IFIP International Conference on Multimedia Computing and Systems (ICMCS'14), Marrakech, Morocco, 2014.

[47] S. A. Mahmoudi and P. Manneback, "MultiCPU/Multi-GPU Based Framework for Multimedia Processing," in IFIP International Conference on Computer Science and its Applications, Sidi Belabess, Algeria, 2015. 